\title{
Feasibility of Using Different Approaches for Recruiting Younger Twins to Establish a Population Based Twin Register in Sri Lanka
}

\author{
Athula Sumathipala', Sisira H. Siribaddana ${ }^{2}$, Nimali De Silva ${ }^{3}$, Nihal M. R. Abeysingha ${ }^{4}$, Sivagurunathan \\ Sivayogam ${ }^{5}$ and Devaka J. S. Fernando ${ }^{6}$ \\ 'Section of Epidemiology and General Practice, Institute of Psychiatry, Kings College, University of London \\ ${ }^{2}$ Sri Jayewardenepura General Hospital, Nugegoda, Sri Lanka \\ ${ }^{3}$ National Twin Registry Project, Colombo, Sri Lanka \\ ${ }^{4}$ Epidemiology Unit, Colombo, Sri Lanka \\ ${ }^{5}$ Department of Community Medicine, Faculty of Medical Sciences, Sri Jayewardenepura University, Nugegoda, Sri Lanka \\ ${ }^{6}$ Department of Medicine, Faculty of Medical Sciences, Sri Jayewardenepura University, Nugegoda, Sri Lanka
}

\begin{abstract}
dentifying twins for a population-based register can be achieved through birth records or community surveys. We studied the feasibility and effectiveness of different methods of identifying and recruiting twins to establish a population based register. To trace twins a population survey was carried out using an interviewer administered questionnaire. We also inspected the birth registration certificates at a divisional secretariat reported from a specified hospital between the years of 1985-1997 and compared it to the birth register of this same hospital. To recruit twins a random sample of 75 twin pairs (150 twins) identified at the Divisional Secretariat were contacted through the post and 25 twin pairs (50 twins) were personally visited. The prevalence of twins was 6.5 twins per 1000 people in the area surveyed. The twinning rate at the hospital was 18.92 twins per 1000 births. A discrepancy of 38 multiples births between the hospital labour room records and those registered at the DS was noted. The response from the postal invitation for recruitment was $59 \%$ and the response from the personal invitation was 68\%. (Difference 9.4\% 95\% $\mathrm{Cl} ; 7.06-11.73)$. Community survey and systematic inspection of birth records either at the hospital or the birth registration office was an effective method to trace twins. Once traced, personal contact was more effective than the postal invitation for recruitment of younger twins. A cost-effective approach would be to use a postal coverage followed by personal contact for non-responders. The alternative method, community coverage, would have financial implications.
\end{abstract}

Sri Lanka is an island with a land area of 65,654 square kilometers. The mid-year estimation of the population for 1997 was 18.6 million with a growth rate of 1.3 percent (Ministry of Health, 1997). Registration of births and deaths has been compulsory in Sri Lanka since 1897. Civil Registration in Sri Lanka is handled by the Registrar General Department, which is headed by the Registrar General. Each of the 9 provinces of the island has an Assistant Registrar General. Each Province is divided into several districts (25 for the island), and the District Secretary (Government Agent) is appointed as the District
Registrar. Each district in turn is divided into several divisions (330 for the island) and the Divisional Secretaries are appointed as the Divisional Registrars. The Divisional Secretariats (DS) are further divided into smaller units, which are the Births and Deaths Registration Divisions. There are 967 such Registration Divisions in the island and each has a Registrar of Births and Deaths.

Grama Niladari Division is the smallest administrative unit, headed by a "Grama Niladari". This position evolved from the traditional Village Headman and is retained in the current administrative structure. The responsibilities of the "Grama Nilardari" include reporting all births in the village to the corresponding Registrar of Births and Deaths. Births occurring in medical institutions are reported to the Registrar of Births and Deaths by the person in charge of the institution. All hospitals in Sri Lanka maintain a register of births in the labour room. They issue a notification, which is then registered by the Registrar of Births and Deaths. Births are registered according to the place of occurrence, and not by the area of the mother's residence. According to the law of the country, births can be registered within 42 days from the date of birth. Therefore, even if the multiple births occur in different places or hours apart (different days), the registration of all births is done together by the Registrar of Birth and Deaths. Births are registered in using triplicate forms. The first copy of the registration certificate is sent to the Divisional Secretary after completion of a book of 100 births. The second copy is also sent to the Divisional Secretary monthly, who

Address for correspondence: Sumathipala A., Clinical Researcher, Section of Epidemiology and General Practice, Institute of Psychiatry, Kings College, University of London, Denmark Hill London, SE5-8AF, U.K. E-mail: spjuats@ iop.kcl.ac.uk 
transmits it to the Registrar General for preservation. The third copy is issued to the family free of charge.

Completeness of birth registration in Sri Lanka is 98.8 $\%$ (Ministry of Health, 1997). The stillbirth rate is 15.5 for 1000 births in the government hospitals (Ministry of Health, 1997). In 1997, 286,938 deliveries occurred in government medical institutions, out of which 2,477 were deliveries of twins or multiples (Ministry of Health, 1997). These 2477 indicate events of deliveries and not the total number of twin children born. The breakdown of twin deliveries in 1997 according to the institution is displayed in Table 1.

However, deliveries carried out in the private sector hospitals are not included. There are approximately 4000 maternity beds in the private sector. The deliveries taking place in the private sector need to be considered for a comprehensive register of twins.

The National Twin Registry of Sri Lanka was initiated in 1997 (Sumathipala et al., 2000). We are now aiming to expand it to a population-based registry. The objective of this work was to test the feasibility and the outcome of different approaches to trace twin births in Sri Lanka. These included a population survey, perusal of hospital birth register and the birth registration certificates at the DS.

\section{Method \\ To Trace Twins \\ Population Survey}

For logistical reasons we selected three Public Health Worker (PHW) areas in the suburb of Colombo. The three PHW divisions include seven Grama Niladari Divisions. The PHW is the smallest health administrative area. This survey was a part of a larger survey carried out by the University of Sri Jayewardenepura. Two medical students were responsible for approaching eighty houses. The medical students used an interviewer-administered questionnaire and interviewed one index person in each visited household. The question "Do you have Twins in the Family" was included in the questionnaire.

If interviewees responded affirmatively to this item, the individuals were given application forms for the National

\section{Table 1}

Total and Twin Deliveries in Sri Lanka in 1997 Categorised by the Type of Institution

\begin{tabular}{lccc}
\hline Type of Institution & $\begin{array}{c}\text { Number } \\
\text { of Institutions }\end{array}$ & $\begin{array}{c}\text { Total } \\
\text { Deliveries }\end{array}$ & $\begin{array}{c}\text { Twin } \\
\text { Deliveries }\end{array}$ \\
\hline Teaching Hospitals & 13 & 65598 & 729 \\
Maternity Hospitals & 02 & 29229 & 235 \\
Provincial Hospitals & 05 & 39473 & 507 \\
Base Hospitals & 31 & 70351 & 635 \\
District Hospitals & 149 & 55132 & 260 \\
Peripheral Hospitals & 104 & 16033 & 70 \\
Rural Hospitals & 133 & 8418 & 30 \\
Maternity Homes & 67 & 2704 & 11 \\
\hline Total & & 286938 & 2477 \\
\hline
\end{tabular}

Twin Registry and were requested to return the completed forms to the Twin Registry by post. Once the information was received, they were either contacted by post or visited to verify the information.

\section{Systematic inspection of hospital records}

We inspected the birth register at the Sri Jayewardenepura General Hospital (SJGH). This newly built hospital was opened and began operation in 1985 . The birth register includes a detail description of the type of birth (singleton/twin/triplets) and the details of the parents. The entries are made under the mother's name because the newborns are often not named at this time. We scrutinised this register for the period of 1985-1997 to trace the multiple births.

\section{Systematic Inspection of Birth Registration Records at a Divisional Secretariat (DS)}

We selected one of 12 DS in the Colombo district because it received notification of deliveries from SJGH. The aim of step 2 and 3 was to look into the compatibility of birth records at the labour room of SJGH, where the births took place and the DS, where the secondary registration of births was undertaken. We inspected only the birth registration certificates of deliveries reported to the DS by the SJGH labour room. The birth registration certificates were available in bundles of 100 , which were maintained in chronological order. Multiple births have their registration certificates adjacent to each other because they are registered together on the same day irrespective of any significant difference in the time and the place of the birth. These were scrutinised for pairs of persons with the same surname, the same name and address of the mother or father, date of birth, and place of birth, to identify twins. These names, dates of birth and the addresses were recorded. A total of 55,800 births, that had taken place at SJGH and had been reported to the DS, were scrutinised.

\section{To Recruit Twins}

Out of the total multiple births traced through DS records (445 sets), a random sample of 100 twin pairs was selected for recruitment. These pairs were randomly allocated into two groups, personal versus postal invitation, with a group size ratio of 1:3. According to power calculations using the programme "power", for a ratio of 1:3 for the two groups, a significance of $5 \%$ and power of 99 , the recommended sample size was 23:69, which we rounded to 25:75. Hence, 75 twin pairs (150 twins) were allocated to the postal invitation group and 25 twin pairs (50 twins) to the personal visit group. The 75 twin pairs in the postal invitation group were posted letters briefly describing the National Twin Registry and inviting them to register. These letters were addressed to the parents of the twins and posted to the address noted in the birth record, with a self-addressed prepaid envelope. Parents of the remaining group of 25 twin pairs were personally visited and invited to register. This was to compare the effectiveness between postal and personal invitation in the recruitment of twins once they were identified through record inspection. 


\section{Results}

\section{Tracing of Twins}

\section{Community Survey Results}

Seventy-four twins (37 twin pairs) were detected during the community survey from a total population of 11,390 who were living in 2913 households. Fifty-seven households (2\%) refused to participate in the survey. Therefore, the prevalence rate was 6.5 twins per thousand people in community in the area surveyed $([74 / 11,390] \mathrm{x} 1000)$. There were $10-\mathrm{MM}$ pairs, 11 -FF pairs and $13 \mathrm{MF}$ pairs (altogether 34 pairs- 68 twins). In total, there were 35 females and 33 males. For two twin pairs we were unable to obtain details, as they were not available on subsequent visits. Between the time of the original survey and subsequent visits for the collection of details, these twins had move from their original address. In one twin pair, the contact person was a female twin but she refused to divulge any information on her co-twin. A summary of the population survey is displayed in Table 2.

\section{Systematic Inspection of Birth Records}

A total number of 49,587 births had taken place at SJGH during the period from 1985 to 1997 . Among these were 48,606 singleton births including 579 stillbirths, thus giving a rate of 11.91 stillbirths per 1000 singleton deliveries $([579 / 48,606] \times 1000)$. There were 483 sets of multiple births, including one set of quadruplets, 13 triplets and 469 twin pairs. Therefore the twinning rate was 18.92 twins per thousand births ([\{469 x 2\}/49,587] x 1000). There were 12 stillbirths among the 469 twin pairs (938 births), giving a rate of 12.79 stillbirths per 1000 twin deliveries ([12/938] x 1000).

The systematic inspection carried out at the DS revealed 445 sets of multiple births (433 twin pairs, 11 triplets and one set of quadruplets) registered at DS for the same period. These 433 twin pairs included 163 MM pairs, $162 \mathrm{FF}$ pairs and $108 \mathrm{MF}$ pairs. The 11 sets of triplets included 01- MMM sets, 02-FFF sets and 8 different sex sets. All 4 of the quadruplets were male.

There was a discrepancy of 38 sets of multiple births between the labour room records at the hospital and the DS for the 12-year period. The stillbirths can account for twelve of these.

\section{Recruitment of Twins}

The response for the postal invitation to register was 59\% ( 44 pairs out of 75 pairs). Four pairs were already members of the National Twin Registry. From the 25 twin pairs in the personal visit group the address of only one twin pair could not be traced. Out of those 24 twin pairs, for whom addresses were identified, 17 were still residing at the same address. Four twin pairs were not available at the original addresses; they were living in rented accommodation at the time of delivery and had left without a trace. Nobody was available at one residence even after two visits, so we did not contact them again. One family had immigrated, and in another family, both twins (one pair) had died two days after registration. The seventeen pairs (68\%) who were available were contacted in person. The parents were requested to register their twins with the National Twin Registry and all agreed.

The percentage difference between the two methods, recruitment through postal invitation $(59 \%)$ and in person visits $(68 \%)$ was $9.4 \%$ (95\% CI; 7.06-11.73)

\section{Costs}

To carry out the community survey we donated 10,000 Sri Lankan rupees to the University. They traced 37 twin pairs (74 twins). This cannot be considered as the real cost as this data collection was supplemented by a larger survey. The time spent tracing twins at the divisional secretariat and making relevant groundwork was 52 days ( 5 working day week) and the cost was 30,000 rupees. Postal costs for 75

\section{Table 3}

Cost Breakdown for Community Survey

\begin{tabular}{ll}
\hline Item & \multicolumn{1}{c}{ Cost } \\
\hline Detecting one pair of twins through birth records & $=$ Rs $30,000 / 447$ \\
& $=$ Rs 67.11 \\
Contacting one twin pair through postal invitation & $=$ Rs $800 / 44$ \\
& $=$ Rs 18.11 \\
Therefore, total cost of detecting twins through & \\
birth records and then tracing through post & $=$ Rs 67.11 \\
& +18.18 \\
& $=$ Rs 85.29 \\
& $=$ Rs $2800 / 17$ \\
For contacting a twin pair through field visits & $=$ Rs 164.71 \\
& \\
Therefore, total cost of detecting twins through & $=$ Rs 67.11 \\
birth records and tracing by a field visit & +164.71 \\
& $=$ Rs 231.82 \\
\hline
\end{tabular}

Note: 1 US\$ $=$ Rs 85.00

Table 2

Summary of the Population Survey

\begin{tabular}{|c|c|c|c|c|c|c|c|c|}
\hline PHM area & Population & $\begin{array}{c}\text { No of } \\
\text { families }\end{array}$ & $\begin{array}{c}\text { No of } \\
\text { families refused } \\
\text { to participate }\end{array}$ & $\begin{array}{c}\text { No of } \\
\text { Twin Pairs } \\
\text { detected }\end{array}$ & $\begin{array}{l}\text { Same sex } \\
\text { MM }\end{array}$ & $\begin{array}{c}\text { Same sex } \\
\text { FF }\end{array}$ & $\begin{array}{l}\text { Different sex } \\
\text { MF }\end{array}$ & $\begin{array}{l}\text { Data on } \\
\text { gender not } \\
\text { available }\end{array}$ \\
\hline Area A & 4730 & 1222 & 23 & 17 & 3 & 7 & 7 & 0 \\
\hline Area B & 3682 & 962 & 22 & 14 & 4 & 3 & 5 & 2 \\
\hline Area C & 2978 & 787 & 12 & 6 & 3 & 1 & 1 & 1 \\
\hline Total & 11380 & 2971 & 57 & 37 & 10 & 11 & 13 & 3 \\
\hline
\end{tabular}


letters containing a questionnaire and a reply paid envelope amounted to 600 rupees and half a day's work by a research assistant, which cost 200 rupees. Therefore, the total cost for postal survey was 800 rupees. The transport costs for personal visits to 25 addresses amounted to 2000 rupees. The research assistant was paid 800 rupees for 2 days of conducting visits. Therefore, the total cost for the in-person contacts were 2800 rupees. Therefore, 33,600 rupees were spent on the project. A breakdown of costs for each component isshown in Table 3 Sri Lankan rupees. (1 US\$ = Rs 85.00)

\section{$\overline{\text { Discussion }}$ \\ Community Survey}

A community survey is accepted as a satisfactory method to obtain a population based twin sample, because it provides figures that are representative (Strachan, 2000). An incomplete response may bias prevalence (Strachan, 2000). However, during our community survey, the refusal rate for families was $1.92 \%$. One weakness of our design is the non-random selection of the $3 \mathrm{PHW}$ areas. Therefore, the findings of our community survey cannot be generalised to the entire Island. Nevertheless, a community survey remains an option as one of the methods to develop a population based twin register. The disadvantage of this method is the need for human resources and increased costs in comparison to other methods. Ascertainment of twins through community surveys is rare, probably because of the high costs of this strategy. However, Finland, Belgium, Germany, Netherlands, Norway, Sweden, Denmark, England and Wales, and Italy have all used population registers as well as birth records to establish large twin registries (Boomsma, 1998).

\section{Systematic inspection of birth records}

One of the reasons for the difference observed between the number of deliveries at the labour room of SJGH and the number registered at the DS was due to stillbirths. The stillbirth rate of 11.91 per 1000 births at SJGH compares favourably with the average of 15.5 per 1000 births for the island.

Delayed registrations may be another explanation, as the law of the country permits birth registration up to 42 days after birth. Non-inclusion of neonatal deaths as live multiple births at the DS may also be a reason. Early neonatal deaths may have been noted as stillbirths, which do not require registration except in "proclaimed towns" (Ministry of Health, 1997). Therefore twin-stillbirths and twin-neonatal deaths are not readily identified and we did not attempt further exploration as to whether neonatal deaths were the reason for the difference of registration between the hospital and birth registration office.

The twinning rate at SJGH was 18.92 twins per 1000 births. The average twinning rate in the government hospitals" (Ministry of Health, 1997) is 17.2 twins per 1000 births in Sri Lanka. There is a wide variation of the twin deliveries per institutions according to the type of institution. The highest rates of twin deliveries occurred in the major hospitals, Teaching, Maternity, Provincial, and Base hospitals. Smaller institutions from District hospitals downward had negligible rates of twin deliveries (Table 1).
As SJGH is a tertiary referral center, twin pregnancies tend to be referred from the peripheral hospitals.

The twinning rate in UK is 11 in 1000 pregnancies (Bryan, 1995); in Japan it is 7 per 1000 births in 1990 (Imaizumi, 1992). In West Bengal, twinning rate was 20.8 for Muslims and 10.57 for Hindus per 1000 deliveries (Das Chaudhuri et al., 1993). The Yoruba race of Nigeria has a twinning rate of well over 40 per 1000 births. Race strongly affects the chance of having twins (Pollard, 1996). African races and particularly Nigerians have the highest rate of twinning. The Oriental (Mongoloid) races have the lowest rates. Caucasians and Indians are somewhere in between (Bryan, 1995). MZ twinning rate is relatively constant and is between 3.5-5 per thousand. The DZ twinning rate varies widely from 3 per thousand in Orientals, to 8 per thousand in Caucasians to 16 per thousand in Africans irrespective of their geographical localisation (Bomsel-Helmreich \& Al Mufti, 1995). We have not yet determined the zygosity of our twins and are unable to report $\mathrm{MZ}$ and $\mathrm{DZ}$ twinning rates. Because the $\mathrm{MZ}$ twinning rate is constant, assuming Sri Lankan MZ prevalence to be around 3.5 to 5 per 1000 births, the estimated DZ rate would be 3.6 to 5.1 per 1000 births.

\section{Recruitment of Twins}

In our study, personal invitation was more effective than the postal invitation for recruitment of twins. Because our random sample allocation was 1 to 4.47 (100 was out of a total of 447 traced at the DS), the findings can be generalised to this birth cohort. However further studies based on larger samples are needed to generalise this finding beyond this sample.

It was evident that 24/25 (96\%) addresses given at the time of birth registration were still in existence and were located, the majority (17/24) were still living at the same address, all of whom agreed to register. Inability to trace younger twins due to internal and external migration occurred at a rate of $21 \%(5 / 24)$, and the death rate was $4 \%(1 / 24)$.

The reasons for non-response $(41 \%)$ to postal invitation, death rate or immigration rates were not explored further, as we were only interested in the response rate (59\%) from the first round without further reminders or visits to the postal survey sample. These aspects were to be explored in the personal visit sample. With the limited resources available to us, our aim was to compare the cost effectiveness between postal invitation and in-person invitation to adapt a strategy for recruitment for future studies, in which postal invitation was the first line to be followed by a visit to the non-responders.

In the new Danish twin registry $92.3 \%$ responded to the postal questionnaire (Kyvik et al., 1995). The Danish twin registry, which is a comprehensive population based registry, was developed using data from the Danish civil registration and information on the number of twin births from the Danish vital statistics office was used as a source of validation. They managed to trace $92 \%$ and had an $85 \%$ response rate to the postal questionnaire (Kyvik et al., 1995). However, any direct comparisons cannot be made 
between these two countries because of the existing social and economic differences.

Although tracing and registering twins through personal visits is satisfactory, this method demands more human resources and funds than postal recruitment. The cost of the personal visit approach to trace and recruit twins, after identification through birth records, are approximately three times higher than that of the postal invitation strategy. However, since the response rate is lower in the postal invitation method, this approach may need to be supplemented with personal visits to recruit the maximum number of twins. A sensible approach would be to use a postal coverage followed by in-person contact for non-responders. Even with this combined approach there will be a percentage that cannot be traced. Therefore, a community survey remains an alternative option to recruit a larger representative sample of twins.

The effectiveness of these methods in tracing and registering an older cohort of twins is not known. The present study involved a younger cohort born within the last 15 years. Migration within the country, away from the country, and continuing internal conflict may affect the tracing of older twins through birth records. Therefore, we need to apply the same method to a cohort of older twins to test the feasibility of using the birth records to trace older twins.

In conclusion, the community surveys and systematic inspection of birth records either at the hospital or the birth registration office are effective methods to trace twins. Once traced through birth records, personal contact was more effective than the postal invitation for the recruitment of younger twins.

\section{Acknowledgments}

Sri Jayewardenepura Hospital, Sri Jayewardenepura University, staff at the Divisional Secretariat, Maharagama,
Wellcome Trust for providing an International Collaborative Research Initiative Grant (ref 060379/2/00/2) grant to continue the work of NTR.

\section{References}

Bomsel-Helmreich, O., \& Al Mufti, W. (1995). The mechanism of monozygosity and double ovulation. In L.G. Keith, E. Papiernik \& D. M. Keith (Eds.), Multiple pregnancy: Epidemiology, gestation and perinatal outcome (p. 33). Canforth: Parthenon Publishing Group.

Boomsma, D. I. (1998). Twin registries in Europe: An overview. Twin Research, 1(1), 34-51.

Bryan, E. (1995). Twins, triplets, and more. London: Multiple Births Foundation.

Das Chaudhuri, A. B., Basu, S., \& Chakraborty, S. (1993). Twining rate in the Muslim population in West Bengal. Acta Geneticae Medicae et Gemellologiae, 42, 35-39.

Imaizumi, Y. (1992). Twining rates in Japan 1951-1990. Acta Geneticae Medicae et Gemellologiae, 41, 165-175.

Kyvik, K. O., Green, A., \& Beck-Nielsen, H. (1995). The new Danish Twin Register: Establishment and analysis of twining rates. International Journal of Epidemiology, 24, 589-586.

Ministry of Health. (1997). Annual Health Bulletin. Colombo: Ministry of Health.

Pollard, R. (1996). Ethnic variation of twining rates in Malawi. Acta Geneticae Medicae et Gemellologiae, 45, 361-365.

Strachan, D. P. (2000). Influence of design on the outcome of twin studies. In T. D. Spector, H. Snieder \& A. J. MacGregor (Eds.), Advances in twin and sib-pair analysis (p. 18). London: Greenwich Medical Media Ltd.

Sumathipala, A., Fernando, D. J. S., Siribaddana, S. H., Abeysingha, M. R. N., Jayasekera, R. W., Dissanayake, V. H. W., \& De Silva, N. (2000). Establishment of a National Twin Registry in Sri Lanka. Twin Research, 3(4), 202-204. 